\title{
"Y LA LLEVARÍA A TIERRA DE PORTUGUESES". RESISTENCIA Y PERMEABILIDAD DE LA FRONTERA IMPERIAL A TRAVÉS DE TRES ESTUDIOS DE CASO*1
}

\author{
"Y LA LLEVARÍA A TIERRA DE PORTUGUESES". \\ RESISTANCE AND PERMEABILITY OF THE IMPERIAL BORDER \\ THROUGH A THREE CASE STUDY
}

\author{
"Y LA LLEVARÍA A TIERRA DE PORTUGUESES". \\ RESISTÉNCIA E PERMEABILIDADE DA FRONTEIRA IMPERIAL \\ ATRAVÉS DE TRES ESTUDOS DE CASO
}

\author{
EMIR REITANO** \\ Universidad Nacional de La Plata \\ JACQUELINE SARMIENTO**** \\ Universidad Nacional de La Plata \\ https://doi.org/10.46553/EHE.23.2.2021.p159-173
}

\begin{abstract}
Resumen
Las diversas formas de resistencia son una respuesta a las imposiciones de normas de conducta y formas de control por parte de la sociedad. Son prácticas que, en muchas ocasiones subvierten el orden y cuestionan la desigualdad. Estas "conductas sociales anómalas", incluían una amplia gama de comportamientos y si ello sucedía dentro de un espacio de frontera como el área rioplatense la situación se tornaba singular por demás. Dado que estamos hablando de relaciones de poder y formas de control social, las fuentes judiciales nos conceden un acceso a esta temática y a la posibilidad de pensar formas de resistencias propias de las mujeres y hombres de la plebe en un espacio de frontera. Estas fuentes ayudan a definir el comportamiento esperado y el castigado. En estos estudios de caso veremos cómo en una frontera imperial permeable se ponen en escena a un grupo de individuos que intentan huir del control estatal y de la justicia sin dejar de lado sus conflictos internos.
\end{abstract}

\section{Palabras clave}

Resistencia - frontera - virreinato - tardocolonial - Rio de la Plata

\footnotetext{
Abstract

The forms of resistance are responses to the impositions of rules of conduct and forms of control. These are practices that, in some cases, subvert order, which question inequality. These "anomalous social behaviors", included a wide range of behaviors. Given that we are talking about

* Fecha de recepción: 10/08/2020. Fecha de aceptación: 09/02/2021.

** ORCID: htpps://orcid.org/0000-0001-7951-217X, Centro de Historia Argentina y Americana. Instituto de Investigación en Humanidades y Ciencias Sociales, Facultad de Humanidades y Ciencias de la Educación. Universidad Nacional de La Plata, Calle 51 entre 124 y 125, Edificio C, oficina 321, B1925ASA, Ensenada, Argentina, ereitano@1psat.com

*** ORCID: https://orcid.org/0000-0001-8924-042X. Centro de Historia Argentina y Americana. Instituto de Investigación en Humanidades y Ciencias Sociales, Facultad de Humanidades y Ciencias de la Educación. Universidad Nacional de La Plata, Calle 51 entre 124 y 125, Edificio C, oficina 321, B1925ASA, Ensenada, jacquelinesarmiento@ymail.com

${ }^{1}$ Este trabajo se encuentra inscripto en el marco del proyecto RESISTANCE - Rebellion and Resistance in the Iberian Empires, 16th-19th centuries, y el Programa Interinstitucional de Historia Atlántica en la Modernidad Temprana de la FaHCE-UNLP.
} 
power relations and forms of social control, judicial sources have made possible an access to this topic and the possibility of thinking about forms of resistance characteristic of underclass. These sources help define the expected behavior and the punished.

Key words

Resistance - border - virreinato - tardocolonial - Río de la Plata

\section{Resumo}

As formas de resistência são respostas às imposições de regras de conduta e formas de controle por parte da sociedade. Estas são práticas que, em alguns casos, subvertem a ordem, que questionam a desigualdade. Esses "comportamentos sociais anômalos", incluíam uma ampla gama de comportamentos, e se isso acontecer em um espaço de fronteira como a região do Rio da Prata, a situação torna-se singular. Dado que estamos falando de relações de poder e formas de controle social, fontes judiciais possibilitaram o acesso a esse tema e a possibilidade de pensar em formas de resistência características da plebe. Essas fontes ajudam a definir o comportamento esperado e o punido. Em estos estudos de caso, veremos como, em uma fronteira imperial permeável, um grupo de pessoas tentam fugir do controle estatal e da justiça sem deixar de lado seus conflitos internos.

\section{Palavras-chave}

Resistência - fronteira - virreinato - tardocolonial - Rio de la Plata

\section{Introducción}

Hace algo más de veinte años, Carlos Mayo y Amalia Latrubesse destacaban que "La frontera es definida como condición, como proceso y como espacio: es un ámbito geográfico y un medio, un dato económico y un fenómeno social. Es todas esas cosas a un mismo tiempo y también un caso de contacto cultural."2 Sin embargo su elasticidad es a la vez su mayor fuerza y su debilidad. Entendiendo de este modo la frontera podemos decir que es también un punto de encuentro entre espacios culturales diversos y, en algunos casos, el borde exterior de la onda expansiva.

En lo que respecta a las relaciones hispanolusitanas en el área rioplatense podemos observar que la misma fue un espacio de constantes intercambios entre españoles y portugueses. Luego del Tratado de Tordesillas el área rioplatense quedó signada como una región de frontera. La imposibilidad de establecer una longitud terrestre y señalar exactamente el lugar donde pasaba la línea imaginaria de Tordesillas dejó definitivamente establecida la región como área de frontera. En esta región las relaciones entre súbditos de España y Portugal fue demasiado particular durante todo el período colonial. Estos individuos percibían la realidad de frontera como lo cotidiano, muy alejado de las perspectivas geopolíticas de las respectivas coronas peninsulares.

A su vez, las formas diversas de resistencia son respuestas a las imposiciones de normas de conducta y formas de control por parte de la sociedad. Son prácticas que, en algunos casos, subvierten el orden y cuestionan la desigualdad. Estas "conductas sociales anómalas", como destaca Susan Socolow, incluían una amplia gama de comportamientos. Dado que estamos hablando de relaciones de poder y formas de control social, las fuentes judiciales nos han posibilitado un acceso a esta temática y a pensar formas de resistencias propias de los diferentes actores en determinados espacios. La frontera es uno de ellos. ${ }^{3}$

\footnotetext{
${ }^{2}$ MAYO-LATRUBESSE, 1998, 15.

${ }^{3}$ SOCOLOW, 2016.
} 
Es sabido que "Resistencia cotidiana" es un concepto teórico introducido por James Scott en 1985 para cubrir un tipo diferente de resistencia; uno que no es tan dramático y visible como rebeliones, disturbios, manifestaciones, revoluciones, guerra civil u otras organizadas como alteraciones colectivas o de confrontación. La resistencia cotidiana es silenciosa, dispersa, disfrazada o aparentemente invisible; algo que Scott denomina "Infrapolitics". Scott muestra cómo ciertos comportamientos comunes de grupos subalternos (por ejemplo, arrastre de pies, escape, sarcasmo, pasividad, pereza, malentendidos, deslealtad, calumnia o robo) no siempre son lo que parecen ser, sino que pueden ser comportamientos de resistencia. ${ }^{4}$

La resistencia cotidiana se trata de cómo las personas actúan en su vida cotidiana con actitudes que podrían socavar el poder. La resistencia cotidiana no se reconoce fácilmente como resistencia pública y colectiva, como rebeliones o manifestaciones, normalmente está oculta o disfrazada, es individual y no está políticamente articulada. Por lo tanto, la resistencia cotidiana representa un especial desafío para la investigación que vale la pena desentramar. ${ }^{5}$

Este trabajo intenta revelar algunas formas de resistencia cotidiana dentro de la permeabilidad de una frontera múltiple como fue la del área rioplatense. Intentaremos también realizar un modesto aporte a la discusión sobre fronteras y resistencias, trabajando con una pequeña escala de análisis y deteniéndonos en ciertas particularidades de una realidad que, sabemos, era más diversificada de lo que se nos presenta a simple vista. Por este motivo se privilegiarán algunos aspectos y se desatenderán conscientemente numerosos elementos y precisiones que tomarían especial interés en un espacio más amplio y adecuado.

En este caso veremos cómo a través de tres hechos concretos [un homicidio, robo de caballos y transporte de desertores] se pone en escena un grupo de individuos integrantes de una gran parte del mosaico étnico que caracterizaba a la sociedad colonial rioplatense y cómo los mismos, intentando huir del control estatal y de la justicia, no dejan de lado sus conflictos internos, los cuales se mantuvieron intactos. María Cuñaminí y María Agustina, a través de un hecho ocurrido en noviembre de 1780, nos revelan esta compleja trama de sucesos mientras que Manuel de Silva en 1758 y Domingo Caravallo en 1769, nos ponen en escena su resistencia dentro de la permeabilidad que tuvo la frontera imperial y sus actores a través del tiempo.

La sociedad tardocolonial rioplatense era una sociedad demasiado compleja, su crecimiento singular y acelerado mantuvo en alerta a la corona que no supo a ciencia cierta de qué modo actuar y cómo resolver los nuevos problemas que se asomaban en todas sus estructuras de poder. Un viejo orden que poco pudo hacer durante su agonía fue el que permitió a estos pequeños actores que hoy nos convocan, a desenvolverse en un espacio de frontera de manera singular, con ciertas libertades de movimiento hasta que, ante las normas alteradas, entró en escena la justicia para desgracia de ellos pero para fortuna de los historiadores contemporáneos que los pudimos visibilizar a través de las fuentes judiciales coloniales.

\section{El escenario: la frontera imperial sudamericana}

Las Misiones Orientales o Misiones del río Uruguay conformaban la región que actualmente abarca el oeste del estado de Río Grande do Sul, al sur del Brasil. En tiempos previos al tratado de San Ildefonso de 1777, el territorio misionero al este del río Uruguay abarcaba una extensión mayor a este estado que incluía parte de Santa Catarina, parte de

\footnotetext{
${ }^{4}$ SCOTT, 2000 y VINTHAGEN - JOHANSON, 2013, 4.

${ }^{5}$ Ibidem, 4.
} 
Paraná y de la República Oriental del Uruguay. A partir del momento de la ocupación portuguesa, el nombre Misiones Orientales quedó restringido a la zona de los siete pueblos ocupados. Esta región histórica, conocida como El Tapé, también era llamada la región de Los Siete Pueblos y Las Once Estancias. Inicialmente formó parte de las Reducciones jesuíticas y de la Gobernación de los Treinta Pueblos de las Misiones Guaraníes, esta última, fue un gobierno creado por la corona española para administrar los territorios que en 1768 debieron dejar abandonados los jesuitas al ser expulsados de sus misiones en territorios que hoy forman parte de la Argentina, Brasil, Paraguay y Uruguay.

La gobernación funcionó intermitentemente entre 1768 y 1810, fecha en que su gobernador adhirió a la Primera Junta de Buenos Aires. Las Misiones Orientales eran los siete pueblos fundados por los misioneros jesuitas al este del río Uruguay que pasaron al poder de Portugal y que luego de la Guerra del Brasil quedaron definitivamente incorporados a este último país. Esta frontera sur de los imperios ibéricos en América fue disputada entre portugueses y españoles prácticamente durante todo el periodo colonial. ${ }^{6}$

A medida que la ocupación de la región se consolidaba, el crecimiento vegetativo de la población y los conflictos se intensificaron. La aplicación de las políticas pombalinas en la región se había iniciado con las tentativas de demarcar límites a través del tratado de Madrid de 1750. A pesar de ser anulado ese tratado en 1761, cerca de tres mil indios de las misiones migraron para la región de Río Grande y de San Pedro y se establecieron en las aldeas de San Nicolás y otras creadas especialmente para recibirlos. Cuando el tratado fue anulado, los portugueses continuaron sus relaciones con los misioneros y no abandonaron la idea de expandir su territorio, incluso incentivando las actividades de intercambio, valiéndose de informaciones de los nativos. ${ }^{7}$

En cuanto a los estudios sobre las fronteras los mismos se han ido diversificando en los últimos años y se han alejado progresivamente de los paradigmas clásicos tradicionales. Éstos, desarrollados desde el siglo XIX al calor de la aparición y consolidación de la formación de Estados-nación y de la adopción de ópticas monolíticas, habían centrado su objetivo historiográfico en la definición territorial del espacio localizado bajo la autoridad de una única soberanía estatal, a partir del trazado de una delimitada y marcada línea de separación. Durante las últimas décadas las nuevas investigaciones sobre la frontera, referidas a realidades históricas propias de las sociedades, están atendiendo las peculiaridades organizativas consustanciales de un complejo Antiguo Régimen en donde la permeabilidad de un espacio multiétnico excede al clásico concepto de frontera rígida y lineal. ${ }^{8}$

Hasta no hace mucho tiempo, y por lo expuesto en los párrafos precedentes, la historiografía destacaba la presencia de los indios en este tipo de conflictos de modo esquemático: los guaraníes establecidos en las misiones jesuitas del Paraguay serían aliados de los españoles en la lucha contra los portugueses, mientras que las poblaciones no sedentarizadas, fundamentalmente charrúas y minuanos, serían auxiliares de los portugueses. A su vez, la clásica historiografía uruguaya, identificó su ser nacional a través de la idea de "Nación Charrúa", como si esta sociedad nativa hubiese estado circunscripta solamente a ese territorio nacional. De este modo la idea de una frontera rígida al servicio de la creación del estado nación, se ponía en evidencia ante estos bandos bien definidos. A través de las fuentes judiciales podemos observar que esa separación estaba más presente en los discursos y en la legislación que en las prácticas mismas, marcadas por las relaciones constantes entre individuos de variado origen étnico y social.

\footnotetext{
${ }^{6}$ FURLONG, 1942, 68.

${ }^{7}$ FRUHAUF, 2011.

8 TRUCHUELO-REITANO, 2017, 19.
} 
En estos espacios de frontera estuvieron presentes demasiados intereses en juego con diferentes prioridades; en lo macroespacial se destacaban las políticas metropolitanas, pero en lo microespacial la lucha por la supervivencia y la resistencia cotidiana nos permiten visibilizar la porosidad de la frontera, las alteridades en relación con ella, su dinámica y sus aspectos cotidianos como lo revelan gran parte de las fuentes judiciales que hemos consultado.

El nexo y la forma de relacionarse entre los individuos de los diferentes grupos sociales y éstos con el gobierno estaba representado por un funcionario, en este caso el alcalde, que surgía del mismo vecindario sobre el que ejercía su autoridad. Dos alcaldes, de primero y segundo voto, eran elegidos anualmente entre los miembros del cabildo local, ejercían en la ciudad la justicia en primera instancia y tenían además funciones policiales. $^{9}$

Algunos autores sostienen que para hablar de justicia en el mundo rural rioplatense debemos hablar de "las justicias". Raúl Fradkin sostiene que no era un equívoco del vocabulario de la época hablar de "las justicias". "Vistas desde el mundo rural "las justicias" eran varias, diferentes y muchas veces superpuestas". ${ }^{10}$

Así, "las justicias" eran los Alcaldes de Hermandad y sus auxiliares, los Alcaldes Ordinarios de los Cabildos, los Oidores de la Real Audiencia, también los comandantes de milicias, los gobernadores Intendentes, los miembros del Tribunal del Consulado y también los Virreyes, los curas y los obispos. "Más aún, muchas veces los paisanos nombraban como "las justicias" a las "partidas celadoras" que incursionaban en la campaña en busca de vagos, cuatreros, desertores o salteadores y este uso perduró hasta bien avanzado el siglo XIX". ${ }^{11}$

¿Qué diferencia existía entre los que administraban justicia en la colonia? La diferencia fundamental se daba entre los "legos" y los "letrados". En este mundo de la colonia en el área rioplatense pareciera que "lego" se acercaba a lo popular y "letrado" a lo culto. Así, letrado hacía referencia al docto, sabio al que tenía algún tipo de instrucción pero a partir de siglo XVII se refería, como hoy, a los abogados y aquellos que manejaban leyes, aunque también lo fueran aquellos que manejaban las letras que otrora fueran las ciencias y entre ellos la teología. Mientras que "lego" que proviene de la voz latina popular, su primera función estaba ligada al mundo religioso, es "lego" quien no tiene órdenes clericales, también el que es falto de letras y noticias, también el que en los conventos de religiosos, siendo profeso no tiene opción a las sagradas órdenes. De este modo este lenguaje religioso se transmitió al mundo de la cultura jurídica de modo directo. $^{12}$

Los que registraban las denuncias judiciales, descargos, testimonios o simples informaciones, por lo general no eran expertos en derecho y en muchas ocasiones el saber de los administradores de justicia provenía de un saber práctico, es decir, sabían hacer un proceso y dominaban la tecnología de la escritura, de este modo se desempeñaban en variadas ocasiones como alcaldes, jueces y en algunos casos como oidores. Según las leyes de Castilla y las que se dictaron para "Las Indias" los alcaldes debían saber "leer y escribir" pero incluso en los márgenes del imperio se dieron casos extremos como el de Mateo Gil, alcalde en la ciudad de Santa Fe durante 1756 que firmaba con una cruz potenzada o por terceros. Este problema parece haberse sucedido durante todo el período colonial en el área rioplatense ya que en los albores del siglo XIX (1801) el Cabildo de la Villa de Luján se vio obligado a renovar la designación del Alcalde de Hermandad de la

\footnotetext{
${ }^{9}$ MALLO, 2004, 89.

${ }^{10}$ FRADKIN, 2007, 11.

${ }^{11}$ Ibidem, 11.

12 BARRIERA, 2008, 350
} 
villa de Navarro porque no encontraban sujetos que sepan leer y escribir para su reemplazo. En 1803 el Cabildo se vio obligado a renovarlo nuevamente por el mismo motivo. $^{13}$

Estos alcaldes venían de estratos sociales intermedios y muchos se quejaban por el desprecio con el que se los trataba. Apoyados por una endeble estructura administrativa que a la vez los sometía a controles constantes debían negociar frecuentemente, en el caso de los alcaldes del mundo rural, con los poderosos locales, con los pares de su sector y con los sectores marginales dentro del espacio de autoridad que le reconocían. ${ }^{14}$

De este modo todos ellos escribían y registraban las voces de los sin letra, de los sectores más bajos. Muchas veces con ella escribían sus sensaciones, opiniones y sus puntos de vista y constituyen el registro que hoy nos queda como testimonio vivo de aquellos individuos que no testaban, no tenían bienes y en muchos casos la historia los perdió de vista. ¿Qué preguntaban estos jueces? ¿Qué contestaban esos hombres y mujeres que eran inquiridos para decir todo lo que supieran? ¿Cómo se puede reconstruir a partir de todos esos testimonios una escucha de lo que quedó en esos corredores transitados por letrados, legos y sectores bajos de la sociedad? Tal vez la respuesta no se encuentre en estas páginas pero algunas aristas asomen de ellas. ${ }^{15}$

\section{Los expedientes}

\subsection{La primera causa}

La primera causa que observamos transcurre en el pueblo de San Miguel en el mes de noviembre de 1780. El sargento de la Asamblea de Dragones y Comandante de los siete pueblos orientales del Uruguay apresó a dos indios, Isidoro Aracuý del pueblo de San Nicolás y otro indio, natural del pueblo de San Juan, llamado Pedro Pablo Cañundé. Ambos estaban acompañados por dos chinas ${ }^{16}$ de los dos dichos pueblos, llamadas María Agustina y María Cuñaminí. Decían que "andaban huidos en aquellos campos y que habían ahorcado a una criatura" $"$.

En su declaración una de las indias dice que:

"Se llama María Agustina, Natural del pueblo de San Nicolás. Cual es la causa de su prisión. Por haber huido con un indio de su pueblo llamado Isidro Aracuý. Preguntado dónde iba con dicho indio y que la han visto con él hasta que los prendieron responde que el dicho Isidro Aracuý le dijo que la llevaría a tierra de portugueses donde él había estado y en la otra banda del monte grande porque le quería volverse a su pueblo la quiso matar."18

También aclara que:

“(...) y mandó a un muchacho de este pueblo llamado Alejo que se montase en un caballo que ella tenía por lo cual ella dijo al dicho muchacho que le quitó el caballo y luego le mandó que le alcanzare un paño para envolver a una criatura de pecho y al tiempo de darle el paño le dio al muchacho una puñalada con el cuchillo en la espalda y luego dijo que la matase y ella montó en el caballo y se escapó y fue a la estancia de San Vicente y dijo al

\footnotetext{
13 Ibidem, 351.

14 MALLO, 1998, 93.

${ }^{15}$ Algunas de estas preguntas se encuentran formuladas en BARRIERA, op. cit., 353.

${ }^{16}$ En el documento las mujeres son nombradas como indias o chinas.

${ }^{17}$ AHPBA- JC - 1780 -34-1-10, f.1.

${ }^{18}$ Ibidem.
} 
dicho capataz de lo que pasaba y luego le vieron los estancieros y prendieron a los que habían estado con ella y entonces supo que habían muerto a su hijo."19

Las fuentes nos revelan mucho más que un infanticidio y un intento de homicidio. La mujer que escapa cuenta al capataz de la estancia los hechos sucedidos y por esta razón es que apresan a los que quieren huir con ella. Sin embargo aquí nos hacemos otras preguntas: ¿Qué motivos llevaron a la india María Agustina a llegar a tierra de portugueses? ¿Cuál fue el motivo de la fuga de estos indios? En ese sentido el expediente no es demasiado revelador, pero el Sargento comandante de estos pueblos orientales muestra celeridad en informar a Buenos Aires del suceso. El año de 1780 no es una fecha casual. A cuatro años de la fundación del virreinato del Río de La Plata y luego del Tratado definitivo de límites de 1777, conocido como Tratado de San Ildefonso, los portugueses cedían la Colonia del Sacramento a cambio de la retirada española de la Isla de Santa Catarina. Todo esto había sucedido también luego de la expedición de Pedro de Cevallos a la región, la cual dejó una fuerte presencia militar. Este expediente nos devela que, a pesar de la militarización, toda la región seguía conformando un espacio muy vulnerable. La militarización había comenzado en la región hacia 1762 cuando Pedro de Cevallos con su fuerza intimó al gobernador de la Colonia del Sacramento a dejar la isla Martín García y ocupó militarmente la fortaleza de Santa Teresa al norte de Maldonado. Esta militarización llevó a pensar que la frontera ganaría en control y rigidez, pero su vulnerabilidad continuó presente como el primer día.

Elisa Frühauf García en su trabajo "Ser índio na fronteira" destaca que el estudio de las relaciones de los indios misioneros, súbditos del rey español con la sociedad luso brasileña, revela cómo ellos utilizaban las disputas fronterizas y la política indigenista portuguesa en provecho propio ${ }^{20}$. Los casos observados nos revelan que ellos no estaban relacionados con un sentimiento de pertenencia, sino que existía un desdoblamiento de acuerdo a la coyuntura en la cual estaban insertos y donde su origen indígena funcionaba como uno de los principales elementos en relación a la sociedad envolvente. Esta identificación no solamente les limitaba espacios sino que también les ofrecía oportunidades.

Así, las categorías étnicas fueron simultáneamente un instrumento de dominación y una forma de supervivencia para las poblaciones indígenas.

Gonzalo de Doblas, administrador y Teniente Gobernador de la Candelaria en el territorio de las Misiones en 1781, comentaba en su "Memoria histórica, geográfica, política y económica sobre la provincia de Misiones de indios guaraníes", de 1785:

"Los indios que desertan llevan regularmente alguna india que no es su mujer, con la que vive como si lo fuera; $y$, ya salga de la provincia o se quede en ella, en todas partes pasan por casados, porque aquéllos a que se agregan, sean indios o españoles, sólo cuidan de disfrutar de su trabajo, sin reparar en que vivan como cristianos o no. Y así ni procuran que oigan misa, ni el que se confiesen, ni que ejerciten ningún acto de cristianos, pues saben que si los quieren obligar a ello se van a otra parte y los dejan; con que, por no privarse del servicio que les hacen, los dejan vivir como infieles." 21

Los portugueses por su parte promovían los ataques a los pueblos de las misiones. En 1771 fueron apresados por las autoridades españolas un grupo de quince portugueses compuesto por un capitán, un alférez, un sargento y 15 soldados. La acusación era seducir

\footnotetext{
${ }^{19}$ Ibidem, f.1,V.

${ }^{20}$ FRÜHAUF, 2011.

${ }^{21}$ DOBLAS, 1836, 128.
} 
a los indios sublevando los pueblos, una de las preocupaciones demostradas por las autoridades españolas era el temor de que los indios pasasen al bando portugués, en ese caso la presencia lusitana era percibida por los españoles como un peligro real, ¿estarían los indios considerando esas propuestas? Probablemente sí. El caso que estamos analizando involucra la relación con los portugueses de una forma implícita, y la huida a sus tierras como un acto voluntario, no por coerción. Queremos destacar esta última figura, la "huida". Si bien la causa involucra la muerte de una criatura, es la huida organizada por un pequeño grupo lo que conduce a la discusión acerca de la dinámica propia de las fronteras en el marco de las resistencias. Pone de relieve, además, la figura de fuerte autoridad de uno de los indios, que tenía experiencia por haber estado ya en tierra de portugueses.

Una particularidad de esta frontera es la fuerte atracción que ejerce la ciudad de Buenos Aires, centralizando los expedientes y movilizando a las personas hacia su espacio. Las formas de resistencia se vinculan así con prácticas de control y espacios destinados a ello. La causa aporta indicios para considerar fundamentalmente la huida pero existen aspectos de otra naturaleza muy importantes para tener en cuenta en lo relacional, en lo criminal y en cuestiones de género, dado que las condenas para cada uno serán diferentes.

María Cuñaminí e Isidro Aracuy fueron trasladados a Buenos Aires. Ella fue sentenciada a cuatro años de reclusión en la Casa de Recogidas e Isidro fue destinado a la Banda Oriental, ocho años de destierro al presidio de Montevideo a servir a ración y sin sueldo en las obras públicas. Para María la consecuencia del proceso fue quedar sometida a un estricto control de sus movimientos y relaciones, desde allí en adelante. En el año 1784 la volvemos a encontrar aún en el Recogimiento, siendo testigo de una Sumaria contra el encargado de la Casa. No hay registros de su salida del lugar, pero lo más probable es que haya sido entregada para servir en alguna casa, en calidad de depósito. Para las mujeres, el cumplimiento de la condena no significaba la libertad, sino sólo pasar de una esfera de control a otra.

\subsection{La segunda causa}

En 1769 una causa abierta contra Domingo Caravallo, Joseph de Manes, Salvador de los Santos y Joseph de Acosta Cardozo (este último portugués, natural de Tras os Montes), nos cuenta que robaban caballos desde esta banda del río en la estancia de San Carlos y los llevaban a vender a los portugueses.

"En el campo del Real de San Carlos a los dos dias del mes de henero deste presente año de mil setecientos sesenta y nueve el Sr Comandante de el Dn Nicolas de Miquelerena, Capitán del Batallón de Buenos Ayres por noticia que tuvo de averse merodeado en estos partidos diferentes gentes forasteras del Rio Pardo y que entre ellos avia venido uno llamado Domingo Caravallo y que avia servido de peon en la estancia de Joseph Acosta Cardozo deste partido de San Juan por lo que aviendo echo asegurar del expresado Domingo Caravallo y conducido presso deste campo mando que el Ayudante de el Subteniente Dn Martin Uriel le hisiese el interrogatorio para venir en conocimiento de los que le acompañavan entre los que trahian con su venida a estos Partidos y licencias con que se avian introducido para llevar a devido efecto esta Sumaria (...)." 22

La causa es por demás compleja ya que abarca a unos cuantos y variopintos personajes: portugueses, porteños de Buenos Aires, un capitán de milicias, un negro

${ }^{22}$ AHPBA, JC-34-1-7- 1769., f.1. 
esclavo, dos indios "de la reducción" y una red de complicidades demasiado amplias y diversificadas en su etnicidad y su regionalidad. Sabemos que salió un grupo de individuos de la estancia de "los mellizos" donde el negro esclavo los esperaba. Desde ahí se dirigieron al Arroyo Grande y luego hacia el Río Pardo. Entre la estancia de los mellizos, ubicada en las proximidades de Buenos Aires y el Río Pardo, en la región de Río Grande do Sul existen casi mil kilómetros, lo que el traslado de 400 caballos, yeguas con sus crías y 50 mulas les llevó un mes y 15 días. Algunos de ellos, los que transportaban el ganado, fueron detenidos en el paraje de San Juan por unos soldados de estaban de ronda. Además de los caballos y las mulas se les encontraron cruces de oro, sortijas con piedras de diversos colores y pendientes de oro. Lo interesante de la causa también es que Domingo Caravalho resulta ser menor de edad y por lo tanto debe intervenir un defensor de menores, lo que complica su resolución.

"Preguntado luego a que falta de la estancia que nombra y en que se empleado. Responde que ha pocos dias de pasada la Semana Santa del año próximo pasado llegó una noche, vino a verle Francisco Batalla empleado de Dn Francisco Suares y le dijo al declarante en que se conchabado que yo lo estoy para llevar hazienda de cavallos, yeguada, para el Rio Pardo a treinta pesos por viaje a lo que le respondió le fuese a esperar al arroyo de los Migueletes a donde acudio el declarante con una tropa de cavallos propios suyos...., se encaminaron al partido de Las Vívoras y Estancia de los Mansilla se mantubieron seis dias por hallarse en este enfermo al cavo de los cuales vio llegar serca de la noche a un portugués llamado Salvador de los Santos y le dijo a Mansilla vamos que todo está pronto, de lo que respondió Mancilla ya que ve como estoy enfermo, y no puedo ir y a poco rato dijo Mansilla me quiere hacer una merced o bien y le respondió Mancilla que le dará Salvador de los Santos los mimos treinta pessos que yo le daría....y se encaminaron de la Estancia del Capitán Canario que distaria una legua $(\ldots)^{23}$

El grupo pone en evidencia que en muchas ocasiones la composición étnica en la sociedad tardocolonial rioplatense era menos importante que el estamento social en donde se podían mover sus protagonistas. Este caso es revelador en ese sentido. Esclavos, indios de las reducciones, libertos, plebe rural y urbana nos permiten visualizar un mundo donde podían interactuar y convivir todos sin mayores conflictos de acuerdo a su rango estamental. Ello constituye otro factor a tener en cuenta a la hora de analizar el rol de cada uno en una sociedad de castas, como también las posibles estrategias de resistencia utilizadas.

\footnotetext{
“(...) en la que se hallaron como cien yeguas encerradas en el corral, de las que apartaron como cincuenta mulas grandes y como cuarenta yeguas con sus crias y quinze burros y se reencaminaron a la costa de San Salvador a la Rinconada de la Estancia de los mellizos pero que desta no salió nadie aunque un negro estava a la puerta y le pidieron se le permitiese encerrar a la cavallada en su corral, no lo permitió, que el siguiente dia se encaminaron al Arroyo... y de alli al Río Pardo en cuyo viaje emplearon un mes y quinze dias conduciendo cuatrocientos cavallos, yeguas con sus crias, las cincuenta mulas grandes ya referidas y cuarenta yeguas con sus crías, lo que se sacó de la estancia del Capitán Canario y de Paredes, y que todas se separaron del Rio Pardo en la Estancia del Portugués Salvador de los Santos ....en el partido de San Juan en el que actualmente se halla entregando en los Paqual el entenado de Lorenzo Santucho de donde avia pasado a ver a Francisco Suares en cuyo rancho fue preso por unos soldados que nunca avía visto." 24
}

\footnotetext{
${ }^{23}$ Ibídem, 3.

${ }^{24}$ AHPBA, JC-34-1-7- 1769, 4-6.
} 
A la hora del juicio las sentencias fueron firmes y variadas, con prisión para la inmensa mayoría. En 1769 todavía la inestabilidad de la frontera imperial era un factor importante y la corona pensaba que sus fragilidades junto a su vulnerabilidad habrían de tener fin con la llegada de Pedro de Cevallos a la región. Esta expedición traería finalmente la ansiada militarización pero, como podemos observar, la misma no fue la solución a todos los problemas regionales. Un robo de esta magnitud no podría pasar desapercibido sin la complicidad de todo un sistema que, a pesar de seguir funcionando, estaba dando síntomas de agotamiento y necesitaba de una transformación. La política borbónica tenía pleno conocimiento de este problema pero la aplicación de sus medidas fue demasiado limitada en sus resultados.

"Siendo esta causa de la mayor consideración en este tiempo por lo mucho que se repiten los robos de los ganados de la otra vanda abasteciendose de ellos los portugueses, se hace necesario que la causa se siga con formalidad y como esto no podrá ejecutarse en la otra vanda como se requiere porque uno de los reos es menor de edad y alguno puede ser indio con loa quales se observan varias formalidades cuia omision invalida lo actuado. Siendo V.E. servido podrá mandar se traigan a esta ciudad los reos para que se les substancie la causa según derecho." 25

Por más que la corona se inclinara hacia el armado de un conjunto de estrategias políticas para reorganizar política, militar y administrativamente un territorio que le resultaba complejo dominar, los protagonistas siempre encontraban un modo de adaptarse a las nuevas estrategias propuestas desde las más altas autoridades imperiales. En ese sentido, ambas coronas peninsulares fracasaron en las decisiones tomadas.

\subsection{La tercera causa}

En este caso un portugués metropolitano llamado Manuel de Silva Ríos, residente en la Colonia del Sacramento y luego trasladado a Buenos Aires, se encuentra con una acusación de bigamia informada al Santo Oficio por tener un matrimonio en Buenos Aires y otro en la mencionada Colonia. Su primera mujer, María Magdalena, residente en la Colonia, así lo denunciaba. Esta causa, fechada en el año 1758, se inició en combinación con la Iglesia y la corona y desencadenó otro problema para el acusado: Silva Ríos transportaba desertores entre ambas orillas del estuario. Este grave problema de frontera llevó a que la causa sobre bigamia quedara diluida o relegada a un segundo plano porque puso en evidencia un problema tal vez mucho más preocupante para la corona en ese momento como era el contrabando y el transporte de desertores en lugar de castigar a un bígamo de manera aislada.

"Hacemos saber a Vuestro Sr como ante nos se nos ha presentado un escrito por Doña María Magdalena Boleno, natural desta ciudad, mujer legitima de Manuel de Silva Rios, Lucitano, cuio tenor con lo cual del proveimos es la siguiente: Sr. Prior Vicario General, Doña María Magdalena Boleno, natural desta ciudad, mujer legítima de Mantel de Silva Ríos Lucitano paresco ante VS como más conbenga y digo que dicho mi marido hallandose de tratante en la Colonia del Sacramento buscando su vida en el ejercicio de Tienda o tendejón se pasó para este puerto hará más tiempo de dos años y ha ando traficando en el Rio en las Corsarias del S. alt. Por que ha sido en estos dias pasados preso en la Fortaleza de Sto Fuerte del Rey, aprendimiento de un Sargento desta Colonia del Sacramento que ha venido a este Puerto a conducir desertores de ella no deviendose entender esto con el dcho mismo porque no esta obligado en la dcha Colonia a servicio de ninguna compañía ni

\footnotetext{
${ }^{25}$ AHPBA, JC-34-1-7- 1769., f. 6.
} 
mando como por el ejercicio que ha tenido en dicha Comandancia que es tan odisa al trafico ilicito de la dicha Colonia a partido los que se interesan en el como en la misma forma sobre todo por ser hombre casado que no es capaz de dexarme desamparada y abandonada siendo mujer de obligaciones expuestas por el mismo causa de miserias y desdichas ademas de que por el ejercicio que ha tenido padecera el puerto en la Colonia las que se deban contemplar por lo que la justificación D. S. se ha deservir clarificar como esta casada con el." 26

Aquí se revela también una trama comercial de contrabando en la que estaban involucrados, en una compleja red comercial que operaba desde la Colonia del Sacramento, grandes mercaderes, pulperos, fleteros, patrones de lancha y empresarios de Montevideo y Buenos Aires. La complicada trama hablaba en la correspondencia de géneros, esclavos y otros productos de Brasil. Rivero de los Santos, otro mercader portugués, operaba desde la Colonia como el contacto fundamental entre los comerciantes portugueses y Silva Ríos era el nexo de los comerciantes de Buenos Aires. En sus transacciones de comercio y contrabando se encontraban vinculados Domingo Lagos, marino y mercader gallego que fue arrestado por contrabandista en 1764 y luego estuvo prófugo junto a otros comerciantes de Buenos Aires como Altolaguirre y Medrano. ${ }^{27} \mathrm{El}$ transportar desertores no era una novedad en la región y la corona no tuvo mucha reacción al respecto porque parecía ser una práctica habitual en el área rioplatense hasta 1777. Luego de esa fecha, seguramente, para transportar desertores se debió ampliar el espacio territorial. No sabemos con certeza cuál fue la sentencia final, pero luego del paso de la Colonia del Sacramento a jurisdicción española nos encontramos a Silva Ríos como mercader y destacado vecino de Buenos Aires. Al parecer la muerte de una de sus esposas alivió en cierta medida su situación ante la iglesia y el Santo Oficio ya que no encontramos información al respecto. Lo cierto es que no tuvo notoriedad su causa como bígamo y ello le evitó ser públicamente expuesto con castigo y advertencia ejemplificadora para los demás. Sin embargo, muchos años después, su sumaria testamentaria se vio afectada por un litigio, tal vez consecuencia de esta bigamia, que involucraba a sus hijos de los diferentes matrimonios los cuales litigaron entre sí. ${ }^{28}$

\begin{abstract}
"Recibi la Carta del VS con data del 31 de mes pasado induciendome copia de los autos que se procesaron por parte y a favor de Manuel de Silva Rios el qual se halla preso en el fuerte desta ciudad por el delito que cometio siendo patron de la Corsaria pequeña de ir por dinero que le dieron por sacar de la Isla Martin Garcia cinco soldados desertores de aquella guarnición como participé a VS por la información que tube del Comandante de la misma Isla en donde es bien pública y manifiesta aquella maldado por declaración de otros soldados que no quisieron acompañar a los fugitivos y sin embargo de estar bien enterado de la realidad del caso no obstante la afectada justificación que hizo en esa ciudad el detenido preso, la qual de ninguna suerte se deberia admitir pues es cierto que para haver yo de escribir a VS carta de oficio sobre semejante hecho había de preceder primero cabal información atendiendo por ende de hallarse el dicho Manuel de Silva casado en esta ciudad y a lo que VS me refiere de parecerle tener bastante mente pregado su delito con la dilatada aprension que tiene padecida. (...)"29
\end{abstract}

La emergencia de una sociedad criolla estratificada produjo una situación en la que los inmigrantes debían ejecutar funciones en los segmentos más bajos de la sociedad. Los nuevos arribos de extranjeros a finales del siglo XVIII y comienzos del siglo XIX seguían

\footnotetext{
${ }^{26}$ AHPBA- JC-34-1-4, 1758, f, 3.

${ }^{27}$ Esta red de contrabandistas y comerciantes se encuentra desarrollada en MOUTOUKIAS, 1992.

${ }^{28}$ REITANO, 2010, 258.

${ }^{29}$ AHPBA- JC-34-1-4, 1758, f, 14, 14 v.
} 
siendo importantes, pero ahora éstos tenían que luchar para ganar su admisión en los peldaños más bajos de la sociedad y dentro de ellos la ilegalidad también ofrecía oportunidades en una sociedad de frontera donde estos actores fueron en gran medida los mentores de su funcionamiento. La mayoría de los portugueses, a pesar de una supuesta legislación vigente en su contra, se arrojaron a la ciudad de Buenos Aires adaptándose a la vida cotidiana rioplatense desde sus remotos comienzos con total normalidad. Esta integración se daba, sobre todo, dentro de los sectores populares artesanales y agrícolas en donde sus actividades encontraban la mayor expresión. Solamente un grupo reducido de extranjeros integró los sectores acomodados vinculados a los grandes comerciantes, tratantes y traficantes.

Los portugueses habían sido un grupo perjudicado por las sospechas que despertaba su situación religiosa, sobre todo en la primera etapa de la colonización. Sin embargo, con el advenimiento del Estado Borbónico, ese concepto se volvió más difuso, complejizándose con el arribo de otras nacionalidades a la región y la aparición de otros conflictos (económicos y políticos) que relegaron a un segundo plano la problemática religiosa respecto a los extranjeros. ${ }^{30}$

\section{Conclusiones}

Las fronteras fueron esos espacios en donde diferentes personas interactuaban de las más diversas formas en el marco de condiciones particulares, y a la vez las coronas desarrollaban instituciones específicas para su control; pero también las fronteras constituyeron un espacio de resistencias cotidianas y las fuentes judiciales se convierten en gran medida en la única voz de esos individuos que alteraban la normativa de este inmenso espacio colonial. Las resistencias en espacios de fronteras implican una diversidad de prácticas que desafían a la misma frontera. Desde que James C. Scott introdujo este concepto en 1985, la investigación ha crecido dentro de campos parcialmente superpuestos, principalmente sectores subalternos, estudios feministas, estudios culturales, campesinos y post-estructurales, lo que justifica clarificaciones dentro de este concepto esquivo. ${ }^{31}$

La permeabilidad de las fronteras aporta una mirada que visibiliza a los individuos apropiándose del espacio y del carácter poroso de la misma. La permeabilidad desafía las formas de control que definen, desde lo formal, dos ámbitos administrativos diferenciados. En este sentido, el primer punto a destacar es la conciencia de la frontera y la utilización de un vocabulario que define esos espacios: "tierra de portugueses", "la otra margen del río", "la otra banda". Las prácticas de resistencia se manifiestan a través de la implementación de estrategias que implican, en ocasiones, el conocimiento del espacio y las normas a ambos lados de la frontera imperial. Las prácticas de resistencia en un espacio de frontera redefinen alteridades ya que ponen en juego alianzas entre grupos que le dan sentido a la propia existencia de la frontera. Y estas alianzas son dinámicas, cambian según el contexto y los sujetos que pongan en relación.

El crecimiento de Buenos Aires a partir de la segunda mitad del siglo XVIII generó nuevas dimensiones en las estructuras sociales y comerciales de la ciudad y la misma, como espacio de frontera, se vio alterada en su conformación. Sin embargo, los portugueses continuaron participando activamente del comercio y el contrabando en la ciudad. También el arribo de lusitanos pertenecientes a todos los estratos de la sociedad se mantuvo constante. Para ellos el área rioplatense continuaba siendo una ciudad más, dentro del espacio atlántico, en la que las circunstancias de crecimiento permitían una

\footnotetext{
${ }^{30}$ REITANO, 2010, 328.

${ }^{31}$ HOLLANDER-EINWOHNER, 2004, 1.
} 
vida mejor, dejando en segundo plano su pertenencia a la corona española, de este modo, entendiendo al área rioplatense como espacio de frontera múltiple en el mundo tardocolonial, nos permite comprender mejor el arribo de estos portugueses que llegaban a la misma con la idea de asentarse y ejercer su ocupación en los roles que la ciudad les permitiese.

Todo ello nos lleva a reflexionar sobre la importancia del espacio en los procesos históricos, los nexos permanentes que unen la historia con el espacio. En ese caso, el tamaño del continente americano y sus distancias ejercieron una verdadera tiranía sobre los imperios ibéricos en América. Los relevamientos cartográficos, administrativos y el control jurídico y militar no hacen más que señalar las dificultades existentes para poder observar tan vastas superficies. ${ }^{32}$

Abordando estas perspectivas de análisis podremos intentar abrir nuevos caminos en la historia para comprender un poco más de nuestra sociedad colonial y su dinámica con una mirada hacia los sectores subalternos, sus formas de resistencia y su vida cotidiana. Como ya señalaba Robert Darnton en su trabajo "La gran matanza de gatos y otros episodios en la historia de la cultura francesa", "apartarse del camino trillado quizá no sea una metodología, pero así se tiene la posibilidad de disfrutar de visiones poco usuales, que pueden ser muy reveladoras para lo que se quiera comprender del pasado".33

Podemos aprender mucho acerca de la historia a través de un análisis detenido de las experiencias extraordinarias de la gente rebelde y común, aunque no sea sencillo rescatarlas más allá de las notas y apéndices del discurso histórico. De esta forma, debemos hurgar por debajo de la historia política, institucional, económica y social para llegar al meollo de la otra historia que encontramos debajo de ella.

En tal sentido, es factible pensar que frente a determinados cambios políticos, sociales y económicos que socavaron las estructuras de poder y el orden tradicional, los individuos tendían a avanzar, retroceder o adaptarse, produciendo una redimensión en las dinámicas de la disputa, los reclamos y las definiciones de las relaciones sociales en general. Eran estas cuestiones las que conducen a preguntarse acerca de los comportamientos de quienes atravesaron los mencionados procesos como también la forma en que se fueron construyendo los espacios de poder, las vicisitudes de las cambiantes relaciones entre los distintos sectores, sus vínculos, adaptaciones, así como las luchas y resistencias entre grupos hegemónicos y subalternos, junto con su proyección hacia la etapa independiente.

Gran parte de la historia de los sectores bajos de la colonia se encuentra en los expedientes judiciales y, aunque los registros y archivos parroquiales complementen la misma, las fuentes, y sobre todo las fuentes judiciales continúan llevando esa carga de contenido que debe interesar al historiador.

En ese aspecto, los habitantes de estas regiones tenían pleno conocimiento del espacio donde podían actuar y la forma de vulnerar los controles coloniales. Por ello, los casos que hoy traemos a referencia pueden ser una pequeña muestra en los que la justicia pudo ser efectiva pero sabemos también que decenas de individuos pudieron evadirla y por ello también evadirnos a nosotros, los historiadores, que en tan efectiva evasión, no pudimos seguirles el rastro.

\footnotetext{
${ }^{32}$ MAYO, 2000, 17.

${ }^{33}$ DARNTON, 1994, 12.
} 


\section{REFERENCIAS BIBLIOGRÁFICAS}

Fuentes primarias

AHPBA- JC-34-1-10,1780. Sumaria criminal actuada en el pueblo de San Miguel contra los indios Isidro Aracuý, Alejo Guañamá y María Cuñaminí por haber ahorcado a una criatura.

AHPBA, JC-34-1-7, 1769. Causa contra Domingo Caravallo, ladrón de Caballos y Joseph de Manes, por llevar a vender caballos al Río Pardo para llevar caballos a los portugueses.

AHPBA- JC-34-1-4, 1758. Autos contra Manuel de Silva acusado de transportar desertores.

Bibliografía

BARRIERA, Darío, "Voces legas, letras de justicia. Las culturas jurídicas de los legos en el Río de la Plata entre los siglos XVI y XIX", en MANTECÓN MOVELLÁN, T. (ed.), Bajtin y la historia de la cultura popular, Santander, Universidad de Cantabria, 2008, 347-368.

DARNTON, Robert, La gran matanza de gatos y otros episodios de la cultura francesa, México, Fondo de Cultura Económica, 1994.

DOBLAS, Gonzalo de, Memoria histórica, geográfica, política y económica sobre la provincia de Misiones, Buenos Aires, Imprenta del Estado, 1836.

FRADKIN, Raúl, El poder y la vara. Estudios sobre la justicia y la construcción del Estado en el Buenos Aires rural. Buenos Aires, Prometeo, 2007.

FRÜHAUF GARCÍA, Elisa, "Ser índio" na fronteira: limites e posibilidades Rio da Prata, c. 1750-1800, Nuevo Mundo Mundos Nuevos [En ligne], Débats, mis en ligne le 31 janvier 2011, consultado el 25 de marzo de 2020. URL: http://journals.openedition.org/nuevomundo/60732 ; DOI: https://doi.org/10.4000/nuevomundo.60732

FURLONG, Guillermo, Los jesuitas, su origen, su espíritu, su obra, Buenos Aires, Luis Gotelli Ed., 1942.

HALPERÍN, DONGHI, Tulio, Revolución y Guerra. Formación de una elite dirigente en la Argentina criolla, Buenos Aires Siglo XXI, 2005.

HOLLANDER, Jocelyn, A.; EINWOHNER, Rachel L.," Conceptualizing Resistance"

Sociological Forum, No. 4, December 2004 (C . 2004), 533-554.

MALLO, Silvia. La sociedad rioplatense ante la justicia. La transición del siglo XVIII al XIX, La Plata, Archivo Histórico de la Provincia de Buenos Aires, 2004.

MAYO, Carlos; LATRUBESSE, Angela, Terratenientes, soldados y cautivos. La frontera 17361815, Buenos Aires, Biblos, 1998.

MAYO, Carlos (ed.), Vivir en la frontera. La casa, la dieta, la pulpería, la escuela (1770-1870), Buenos Aires, Biblos, 2000.

MOUTOUKIAS, Zacarías, "Redes, autoridad y negocios: racionalidad empresaria y consenso colonial en Buenos Aires (Segunda mitad del siglo XVIII)", en Annales, Économie, Société, Civilisations, vol. 47, No. 4-5, París, Presses universitaires de France, julio-octubre 1992, 889915.

REITANO, Emir, La inmigración antes de la inmigración. Los portugueses de Buenos Aires en vísperas de la Revolución de Mayo, Mar del Plata, Editorial de la Universidad Nacional de Mar del Plata, 2010.

SCOTT, James, Los dominados y el arte de la resistencia. Discursos ocultos, México, Nueva Era, 2000.

SCOTT, Joan, "Gender as a useful category of historical analysis". En Culture, society and sexuality, London, Routledge, 2007, 77-97. 
SOCOLOW, Susan, "La mujer y las conductas sociales anómalas: delito, brujería y rebelión", en Las mujeres en la América Latina colonial, Buenos Aires, Prometeo, 2016, 183-202

VINTHAGEN, Stellan; JOHANSON, Anna, "Everyday Resistance: Exploration of a Concept and its Theories". Resistance Studies Magazine, 1, 2013, 1-46.

TRUCHUELO, Susana; REITANO, Emir, Las fronteras en el mundo atlántico (siglos XVI-XIX). La Plata, Universidad Nacional de La Plata. Facultad de Humanidades y Ciencias de la Educación. (HisMundi; 1), 2017, p. 19. Recuperado de: http://libros.fahce.unlp.edu.ar/index.php/libros/catalog/ book/85. 